\title{
A FUNÇÃO SOCIAL DA DECISÃO JURÍDICA NO DIREITO CONTEMPORÂNEO
}

\author{
Ana Augusta Rodrigues Westin Ebaid ${ }^{1}$ \\ ${ }^{1}$ Docente do Curso de Direito da Universidade do Oeste Paulista - UNOESTE
}

\section{RESUMO}

O presente trabalho direciona-se a analisar e explicar a teoria da decisão jurídica, demonstrando a sua relevância para a concretização dos direitos. Verifica-se que a sistemática jurídica tem se manifestado sob variadas formas, desde o aparecimento do dogmatismo jurídico às novas concepções da sociedade moderna que superaram o pensamento dogmático. Os estudiosos do Direito não têm medido esforços com o objetivo de elaborar uma teoria que estruture o ordenamento jurídico definindo os parâmetros para a difícil tarefa que é a aplicação do direito. Assim, à medida que a sociedade se torna mais complexa, surgem novas situações que requerem uma maior flexibilidade do direito. Nesse contexto, o desenrolar do direito pode ser superado por outras formas de racionalidade. A propósito, este é um dos maiores desafios que o jurista enfrenta hoje, pois emitir um juízo acerca das controvérsias jurídicas é uma tarefa que requer uma imensa dose de criatividade, porquanto o direito é uma ciência que envolve, acima de tudo, contingências.

Palavras-chave: Decisão Jurídica, Função Social, Direito Contemporâneo.

\section{SOCIAL FUNCTION OF LEGAL DECISION IN MODERN LAW}

\begin{abstract}
This work directed to analyze as much as explain the theory of legal decision, this way showing its relevance for the concretization of the rights. $t$ can be seen that the legal systematic has been expressed in several ways, since the forthcoming of legal dogmatism to the new conceptions of our modern society, these ways have surpassed the dogmatic thinking. The law scholars have put all their efforts, aiming to elaborate a theory that brings a structure to the legal system, thus defining the parameters to the tough task which is the law enforcement. Therefore, as the society becomes more and more complex, new situations arise and they demand a greater law flexibility. In this context, the law unfolding can be surpassed by other ways of rationality. By the way, this is one of the most complex challenges the jurist faces nowadays, and on this account to make a judgment issue on legal disputes has become a task that requires a big deal of creativity; this way law is a science that involves, most of all, contingencies.
\end{abstract}

Keywords: Legal Decision, Social Function, Contemporary Law. 


\section{INTRODUÇÃO}

O direito pode ser considerado 0 instrumento civilizatório de maior importância, que o Estado detém, existindo por meio de mecanismos que representam a evolução da sociedade.

A ideia de ordem é pressuposta da existência do direito, visto como um conjunto lógico, sistemático e coerente representado por normas que retratam a existência de uma sociedade homogênea. No entanto, sob a inspiração da sociedade moderna, marcada por sua complexidade e assumida por características heterogêneas, hoje assume novos contornos uma perspectiva mais aberta.

Frente a este paradigma, será feita uma análise da função civilizatória do direito, sobretudo no que tange o aspecto da decisão jurídica. A importância do estudo será em pautar a generalidade das leis diferenciando da tarefa desempenhada pelo juiz, que se dá pela escolha de uma norma individual para cada situação que o direito deve abrigar.

A amplitude que alcança uma interpretação é imensurável, pois se percebe com a vivência jurídica, que o direito convive com uma carga axiológica, exigindo do intérprete uma imensa dose de criatividade. A propósito, este é um dos maiores desafios que o jurista enfrenta hoje, porquanto adaptar as regras jurídicas às novas e constantes condições da realidade social, os leva a julgar de modo cada vez mais responsável.

O caminho para o desenvolvimento do presente trabalho será o estudo da decisão jurídica, mediante a qual os juízes, no momento de proferir suas decisões, devem estar comprometidos com os pressupostos de uma verdade real, e não meramente formal, procurando almejar, de forma incansável, a realização da justiça, atendendo os anseios da maioria da sociedade.
Os procedimentos metodológicos reconstruirão os horizontes teóricos envolvidos com a teoria da decisão jurídica, analisando o que ocorre, quando os juristas e atores do direito se entregam à tarefa de criar, interpretar, aplicar e integrar o direito frente às novas perspectivas que conduziram a uma profunda revisão no modo de se encarar o direito.

\section{DIREITO E SOCIEDADE}

O direito é fruto de uma realidade social que, para a consecução dos seus objetivos, dispõe de um conjunto de instrumentos, visando a manutenção da paz, da segurança e do bem estar comum, impostos por modelos culturais, dos ideais coletivos e dos valores que persegue, tornando a convivência humana possível.

Pode-se afirmar que a ideia do direito está presente, a todo momento, na sociedade. A própria experiência cotidiana revela, espontaneamente, múltiplas operações da atividade jurídica, ao realizarem um negócio de compra e venda, alugar, casar, ter filhos etc.

Nota-se que o direito surge e se desenvolve na sociedade, assegurando padrões mínimos de comportamento, para que a convivência social seja possível. A causa dessa correlação entre sociedade e direito, conforme alude Cintra, Grinover e Dinamarco, (1998, p. 19)

está na função ordenadora que o direito exerce na sociedade, isto é, de coordenação dos interesses que se manifestam na vida social, de modo a organizar a cooperação entre pessoas e a compor os conflitos que se verificam entre os seus membros.

O direito assume seus contornos conforme as perspectivas da sociedade, prescrevendo as relações jurídicas que se formam entre as pessoas. Por isto, o direito é uma ciência dinâmica, exigindo que, a cada época, acompanhe os anseios e os interesses da 
sociedade para o qual foi criado.

Sob este aspecto sociológico, os autores Cintra, Grinover e Dinamarco, (1998, p. 19) observam que o direito

[...] é geralmente apresentado como uma das formas - sem dúvida a mais importante e eficaz dos tempos modernosdo chamado controle social, entendido como o conjunto de instrumentos de que a sociedade dispõe na sua tendência à imposição dos modelos culturais, dos ideais coletivos e dos valores que persegue, para a superação das antinomias, das tensões e dos conflitos que lhe são próprios.

Na verdade, a ideia do direito é muito mais abrangente, podendo ser definido como um instrumento único, apresentando características singulares, inconfundíveis por sua especificidade, buscando a máxima realização dos valores humanos, baseado em critérios que visam a alcançar a realização da justiça.

A ideia de realização de justiça, segundo Hespanha (1977, p. 61) "é a vontade constante de dar a cada um o que é seu (iustitia est constans et perpetua voluntas ius suum cuique tribuendi)."

O conhecimento do direito é uma tarefa difícil, pois, muitas vezes, são apresentadas formulações contraditórias, preceitos obscuros ou incompletos, fontes concorrentes, além de problemas relacionados à hierarquia das fontes e à interpretação de cada uma delas.

Sob este prisma, a aplicação do "direito" à situação de "fato" revela-se, na prática, uma das relações mais complexas para a teoria jurídica, em razão de os fatos submetidos à aplicação do direito possuírem extrema variedade.

Ao longo dos anos, algumas teorias tentaram exercer certa influência no modo de interpretar o sistema jurídico. Entretanto, nenhuma delas foi capaz de exaurir qual seria a melhor forma de aplicar o direito a uma situação existente. Portanto não existe nenhuma teoria que explique os modos de operação do sistema jurídico.

A maneira como 0 direito deve ser aplicado exige de quem o faz uma lógica própria, que exige, além da hermenêutica jurídica, o envolvimento de todo um raciocínio com múltiplas particularidades. Nota-se que o raciocínio jurídico é envolvido por múltiplas particularidades, uma vez que se apresenta como um fenômeno complexo e também variável.

O direito passa a ser singularizado com a decisão do juiz, que constitui momento criativo para além da singela aplicação de normas.

Entre os conceitos que descrevem uma situação de fato, até a designação da hipótese legal que a circunstância exige daquele que vai aplicar o direito, um desempenho fundamental, pois o direito é uma ciência que envolve, acima de tudo, contingências.

$\mathrm{Na}$ realidade, esse processo de aplicar uma hipótese legal a uma situação de fato faz transparecer a idéia de que a decisão jurídica possa ser obtida por meio de um procedimento lógico.

Entretanto, no campo jurídico, existem muitas maneiras distintas de se pensar cada situação, posto que o direito comporta inúmeras definições e posições, aliás, muitas vezes, de forma radicalmente contrapostas, não sendo possível caracterizá-lo como um saber meramente técnico.

Significa dizer que o direito não pode ser identificado por um método, visto que a essência do direito está marcada por sua constante mutação. É justamente por isto que os problemas de definição e de interpretação do sistema jurídico permeiam os problemas da decidibilidade.

É neste sentido que o professor Ferraz Jr. (2006, p. 90) observa que a decisão "não é um mero ato de escolha, possível em situações 
simples, que não constituem a regra nas situações complexas, onde as avaliações não são nítidas nem as alternativas são tão claras".

Essa coordenação de procurar as condições de decidibilidade se caracteriza por múltiplos fatores. Verifica-se, assim, que muitos são os elementos que concorrem para a estruturação do direito, bem como seus impactos na obtenção das decisões jurisdicionais.

Por esta razão, diz-se que o direito pode ser comparado à obra que está constantemente sendo construída, uma vez que, a todo o momento, surgem novos conflitos na sociedade, reclamando o reconhecimento do direito e exigindo a manifestação do judiciário.

\section{A DECISÃO JURÍDICA E A CONSTITUIÇÃO DO DIREITO}

A decisão jurídica é um dos elementos mais importantes na constituição do direito, constitui momento criativo, eis por que o papel do juiz é particularizar soluções por meio de disposições generalizadas.

Quanto ao papel do magistrado, o jurista Carlos Aurélio Mota de Souza, lembra que o juiz é um intermediário que transforma o comando abstrato da lei em um efetivo instrumento de justiça.

Nas palavras do autor,

A distância que medeia da lei abstrata à decisão concreta é um espaço preenchido somente pelo juiz. Este se apresenta em atitude constante de curiosidade, inquietude, reflexão: para ele, individualizar a norma é humanizar o direito; olhar a pessoa que vive um litígio ou conflito é fazer com que o processo seja real $\mathrm{e}$ efetivo instrumento de justiça. (SOUZA, 1996, p. 129)

De fato, a interpretação e a aplicação do direito possuem um conteúdo eminentemente vinculado à experiência humana, razão pela qual o juiz deve estar atento às peculiaridades de cada caso, devendo sempre buscar soluções justas, aproximando o direito da realidade.

A liberdade conferida ao juiz, para julgar, seguindo uma consciência social, apresentando determinados valores aos fatos debatidos, retira a decisão do formalismo, de sorte que a lei não seja aplicada como o único instrumento na busca da efetivação da justiça.

É neste sentido que Souza (1996, p. 137) observa que o julgador deve ter uma visão estática do passado e dinâmica do presente.

[...] entendemos que o intérprete (administrador e julgador) tem um olhar posto na lei genérica, que deve interpretar e aplicar a uns poucos, concretamente (visão estática do passado, porque a lei não muda) e outro olhar na elaboração de uma regra prática, de dever-ser, válida e eficaz para as partes em conflito (visão dinâmica do presente) porque, análogo ao legislador, deve contribuir e sabe que suas decisões influirão no ordenamento jurídico [...]

Verifica-se, dessa forma, que a decisão jurídica pode ser considerada uma importante fonte de produção normativa. Daí a relevância do juiz exercer papel inovador na ordem jurídica, devendo estar sempre atento as constantes transformações do mundo moderno.

Nota-se que, nos dias atuais, o direito não se manifesta apenas por meio de leis. Hoje se verifica que os princípios gerais de direito, a garantia dos direitos fundamentais, a cultura dos direitos humanos, o dever de concretização dos direitos de cidadania assumem uma importância cada vez maior em virtude de seu caráter sociológico, delineando uma nova chave de leitura e interpretação jurídica.

A Constituição Federal de 1988 traz uma gama de princípios que retratam os valores da sociedade, destacando-se, entre eles, o princípio 
da dignidade da pessoa humana, da proporcionalidade e da razoabilidade como valores fundantes da ordem jurídica.

Observa-se que a valoração desses princípios requer o exercício de uma atividade mental, que deve ser realizada pelo julgador. Neste sentido, é oportuno lembrarem-se as reflexões provocadas por Alexy (2005, p. 16). O autor aponta que "a teoria dos princípios oferece um ponto de partida adequado, para atacar as teses positivistas de separação entre Direito e Moral".

Outro aspecto que o autor esclarece é que os princípios devem ser aplicados, levandose em conta a ponderação dos graus. A apreciação desses princípios é estabelecida por uma ordem em que devem ser ponderados os valores determinados por critérios morais.

Dessa forma, fica claro que o trabalho do juiz não consiste, simplesmente, na mera aplicação de uma norma a um fato, por ser uma tarefa complexa, visto que o direito é uma ciência que envolve, acima de tudo, contingências.

A amplitude que alcança uma interpretação é imensurável, pois se percebe com a vivência jurídica, que o direito convive com uma carga axiológica, exigindo do interprete uma imensa dose de criatividade. A propósito, este é um dos maiores desafios que o jurista enfrenta hoje, porquanto adaptar as regras jurídicas às novas e constantes condições da realidade social, buscando soluções, observando os princípios constitucionais, os leva a julgar de modo cada vez mais responsável.

Os tempos atuais exigem novas formas de trabalhar com o direito, fundados em práticas capazes de construir uma cultura jurídica que venha a ter uma maior preocupação com o social, focalizando uma maior proteção dos direitos, voltados ao pleno desenvolvimento das relações humanas.

Conforme se constata da lição de Martins, invocada por Souza (2006, p. 35)

O Direito moderno já não
admite a visão estreita do
positivista nem a redução do
campo de abrangência de seu
cientista, dicção perfeita e pura.
Exige um interprete humanista,
universal, com ampla visão dos
fenômenos sociais e de suas
manifestações nas mais
variadas ciências.

Seguindo esta linha de raciocínio, vislumbra-se desenvolver uma nova chave de interpretação jurídica, mediante a qual os juízes, no momento da decisão, devem estar comprometidos com os pressupostos de uma verdade real, e não meramente formal, procurando almejar, de forma incansável, a realização da justiça, atendendo os anseios da maioria da sociedade.

Uma forma de se proceder a uma interpretação inovadora pode ser quando o juiz se entrega a tarefa de compreender o "espírito da lei", ou seja, entender qual é o sentido da lei, pois toda norma tem um sentido. É na busca deste sentido que o direito se realiza, e não na fiel interpretação da letra da lei.

É neste sentido que o saudoso professor Montoro (2003, p. 40) afirma que "o juiz não é apenas um executor da lei, não é um escravo da justiça, ele é um realizador da justiça."

A propósito, o autor lembra um claro exemplo, situando a condenação radical do formalismo jurídico.

Numa estrada de ferro, na Bélgica, existe uma placa: "É proibida a entrada de cães". Chega um homem com um urso e quer entrar. O guarda diz: "O Senhor não pode entrar". A isto o homem responde: É proibida a entrada de cães, urso não é cão, logo eu entro", afirma ele dentro dos parâmetros do Positivismo Jurídico e da interpretação literal. Mas urso é pior do que cão! Tentemos fazer uma analogia, mas, relativamente ao 
Direito Penal, não será possível, pois não a admite, o que fica asseverado no brocado nulum crimem sine legem. $\mathrm{Na}$ sequência da história, chega um herói de guerra, cego, conduzido por um cãozinho inofensivo e o guarda o deixa entrar. (MONTORO, 2003, p. 40-41)

O autor segue explicando:

Aqueles que tem uma concepção formalista dizem: "É preciso mudar a tabuleta", ou seja, os cães e outros animais [...] Eu digo: Meus amigos, é o apego à letra da lei e nós sabemos que existe a escritura. A letra mata. É o espírito que salva. Qual é o espírito desta lei? Essa lei tem espírito? Claro que tem! Toda lei, toda norma tem um sentido! E esse sentido é sempre a defesa da pessoa humana. No caso citado, por que é proibida a entrada de cães? Qual é o espírito daquela lei? Ela existe porque é vontade do chefe da estação, que é a autoridade competente. Ela é lei e o seu espírito é defender a pessoa humana, para que não seja mordida. Este é o sentido. Ora, o urso não é cão, mas morde. E o outro é cão, mas é inofensivo, não morde. Ele interpretou e esta é a função do direito. (MONTORO, 2003, p. 41)

Para contextualizar estas idéias, torna-se pertinente aludir as reflexões provocadas por Souza (1996, p. 258)

[...] o juiz deve encarnar a Justiça, lançando um olhar abaixo (para as circunstancias do fato) e outro acima (para o direito justo, a equidade), servindo-se da lei apenas como guia ou farol, o que significa decidir sempre a par da lei, mas buscando resultado além dela própria.

A aplicação do direito, visando somente à obediência das leis é uma visão retrógrada. Muitas vezes, não consegue atingir sua maior finalidade, que é a realização da justiça É indispensável que o juiz tenha sensibilidade de compreender a essência de cada lei. Aliás, este é um dos maiores desafios que o juiz encontra na contemporaneidade. Para tanto, torna-se necessário romper com esta concepção arcaica de produção, interpretação e aplicação das leis, procurando condicionar as decisões judiciais à procura do justo, buscando a realização da justiça.

\section{CONSIDERAÇÕES CONCLUSIVAS}

Verifica-se que a aplicação do direito se revela na prática, uma das operações mais complexas, pois muitos são os elementos que concorrem para sua estruturação.

O tema relacionado com o problema da interpretação jurídica pode ser apreciado de diferentes formas. Um dos caminhos possíveis tem como propósito situar o direito moderno sob uma perspectiva funcional, viabilizando novos critérios, para que o conhecimento do direito venha a se preocupar com atender os interesses da sociedade, sem a necessidade de grandes conceituações.

Neste âmbito, busca-se encontrar explicações sobre a validade do direito, entendendo suas funções sociais. Para isto, o melhor seria flexibilizar a aplicação do direito, conforme os imperativos sociais ou ponderação do julgador.

Desse modo, um novo cenário jurídico passa a ser construído, marcando o desenvolvimento de novos processos interpretativos, com o fim de trabalhar questões que envolvem apreciação de valores e sob os 
quais não se podem subtrair conclusões lógicas ou formais.

Daí a necessidade de os julgadores buscarem novas perspectivas, pois não há duvidas de que se está vivendo uma fase pósmoderna, na qual o direito deve acompanhar as evoluções sociais e atender as necessidades desta sociedade

\section{REFERÊNCIAS}

ALEXY, R. Teoria da Argumentação Jurídica. 2.ed. São Paulo: Landy Editora, 2005.

BARROSO, L. R. Direito Constitucional Contemporâneo: Os conceitos fundamentais e a construção do novo modelo. São Paulo: Editora Saraiva, 2009.

CINTRA, A. C. de A.; GRINOVER, A. P.; DINAMARCO, C. R. Teoria Geral do Processo. 14.ed. São Paulo: Malheiros, 1998.

FERRAZ JR, T. S. A Ciência do Direito. 2.ed. São Paulo: Atlas, 2006.

FERRAZ JR, T. S. Introdução ao Estudo do Direito: técnica, decisão, dominação. 3.ed. São Paulo: Atlas, 2001.

HESPANHA, M. A. Panorama Histórico da Cultura Jurídica Européia. Portugal?:

Publicações Europa-América, Ltda, 1977.

MONTORO, A. F. Estudos de Filosofia do Direito. 2.ed. São Paulo: Saraiva, 1999.

MONTORO, A. F. 50 Anos de Direitos Humanos. In: SOUZA, C. A. M. R. B. (or.). A Cultura dos Direitos Humanos - Importância da Declaração do Direito do Homem no Século XX. São Paulo: Editora Themis, 2003.

SOUZA, C. A. M. Motivação e Fundamentação das Decisões Judiciais e o Princípio da Segurança Jurídica. Revista Ibero Americana de Direito Público, Rio de Janeiro, América Jurídica, v. XX, 2006.

SOUZA, C. A. M. Segurança Jurídica e Jurisprudência: Um enfoque filosófico-jurídico. São Paulo: Editora LTR, 1996. 